
22

\section{Poleward expansion of the tropical belt derived from upper} tropospheric water vapor

$$
\text { Qinglong You }{ }^{1,2 *} \text {, Jinzhong Min }{ }^{1} \text {, Shichang } \mathrm{Kang}^{3} \text {, Nick Pepin }{ }^{4}
$$

1. Earth System Modelling Center (ESMC); Key Laboratory of Meteorological Disaster, Ministry of Education; Collaborative Innovation Center on Forecast and Evaluation of Meteorological Disasters; Nanjing International Academy of Meteorological Sciences (NIAMS); Nanjing University of Information Science and Technology, Nanjing, 210044, China;

2. Open Research Fund Program of Plateau Atmosphere and Environment Key Laboratory of Sichuan Province, Chengdu, 610225, China;

3. State Key Laboratory of Cryospheric Science, Chinese Academy of Sciences (CAS), Lanzhou 730000, China;

4. Department of Geography, University of Portsmouth, PO1 3HE, U.K.

* Corresponding author E-mail address: yqingl@126.com Resubmitted to International Journal of Climatology, April 22, 2014 \title{
7
} 18 9 20 21

\section{Abstract:}


Based on intersatellite-calibrated high-resolution infrared radiation sounder (HIRS) upper tropospheric water vapor (UTWV) brightness temperatures, the width of the tropical belt is defined as the distance between the latitudes at which maximum HIRS UTWV brightness temperatures are recorded in both hemispheres. Poleward expansion of the tropical belt is evident during 1979-2013 on an annual basis, with an average global magnitude of 1.57 degrees latitude per decade. Most rapid widening is evident in the west Pacific, in agreement with the strengthening of the Walker Circulation over time. This research suggests that the HIRS UTWV brightness temperatures are a good proxy to investigate expansion of the tropical circulation in low latitudes.

(n)

34

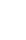
36

\section{7} 38 39 40 41 42 43 44

\section{Introduction}


Widening of the tropical belt has been evident since the beginning of the satellite era (1979) and is expected in the context of recent climate warming (Lu et al., 2007; Lu et al., 2009; Seidel et al., 2008). This will profoundly influence the global climate system and has important implications for subtropical and tropical societies. For example, poleward movement could result in shifts in precipitation patterns affecting natural ecosystems, agriculture and water resources (Seidel et al., 2008). As a consequence, study of the widening of the tropics has been a common theme in the scientific community (Hu and Fu, 2007; Hu et al., 2011; Lu et al., 2007; Lu et al., 2009; Reichler, 2009; Seidel et al., 2008). Recent studies have been concerned with the definition and the boundary of the tropical belt (Fu and Lin, 2011; Hu and Fu, 2007; Hu et al., 2011; Johanson and Fu, 2009; Lu et al., 2007; Lu et al., 2009; Seidel and Randel, 2007) but it is still the case that the boundaries of the tropics vary between different studies and there is not one unique accepted definition.

The poleward extent of the tropics depends on the definition of specific indicators of tropical width, which can be roughly divided into two categories (Reichler, 2009). One contains dynamical indicators which concentrate on characteristic features of the atmospheric circulation at the outer edges of the tropics, such as the poleward boundary of the Hadley circulation ( $\mathrm{Hu}$ and $\mathrm{Fu}, 2007 ; \mathrm{Hu}$ et al., 2011; Korty and Schneider, 2008), the position of subtropical jet cores (Archer and Caldeira, 2008; Reichler et al., 2003; Reichler, 2009), and the latitude where the surface winds change from westerly to easterly (Žagar et al., 2011). The other category includes physical indicators which exhibit relatively sharp gradients at the tropical edge. These include the amount of outgoing longwave radiation (OLR) (Hu and Fu, 2007; Hu et al., 2011), the concentration of stratospheric ozone (Hudson et al., 2006), the height of the thermal tropopause (Lu et al., 2007; Lu et al., 2009; Seidel and Randel, 2007), the relative humidity of the air, and the surface water balance (difference 
between surface precipitation and evaporation).

Many previous studies have focused on atmospheric climate variables, and relatively little attention has been paid to upper troposphere water vapor (UTWV) (>400hPa), despite the fact that the tropical circulation is three-dimensional. Previous studies have used high-resolution infrared radiation sounder (HIRS) OLR (outgoing longwave radiation) data to define the tropics ( $\mathrm{Hu}$ and $\mathrm{Fu}$, 2007). However, UTWV brightness temperatures are able to trace the presence or absence of deep convection in the tropics (Bates et al., 1996). This study attempts to use these to define the width of the tropics and therefore to study long-term trends in widening over the satellite era (1979-2013).

\section{Data and Methods}

Three decades of inter-satellite calibrated HIRS channel 12 clear-sky measurements of UTWV have been created (see Shi and Bates, 2011). Cloudy pixels were removed from the HIRS data using a simplified method based on the International Satellite Cloud Climatology Project (ISCCP) cloud detection approach (Jackson and Soden, 2007), because variable cloud conditions at different observation times of different satellites arean additional influence on the brightness temperatures.

Clear sky data (uncontaminated by cloud effects) can explain many differences in satellite measurements (Shi and Bates, 2011). The resulting time series has been calibrated to take differences between satellites into account. The monthly HIRS UTWV brightness temperatures cover 1979 to 2013 with a spatial resolution of $2.5^{\circ} \times 2.5^{\circ}$, and are available from http://www.ncdc.noaa.gov (Shi and Bates, 2011). The HIRS UTWV brightness temperatures can be interpreted both in terms of water vapor variability and dynamics, especially in the tropics and subtropics (Bates et al., 2001). Higher brightness temperatures respond to lower water vapor content 
(drier air) and relate to areas of subsidence in the topical troposphere (Soden \& Betherton 1993).

Thus the latitudes of the descending limbs of the Hadley circulation in each hemisphere can be identified by locally high brightness temperatures, or brightness temperatures above a given threshold.

The Mann-Kendall test for a trend and Sen's slope estimates were used to detect and estimate trends in HIRS UTWV brightness temperatures and the latitudinal position of their values (Sen, 1968). A trend is considered to be statistically significant at the $5 \%$ level $(p<0.05)$.

\section{Results}

Figure 1 shows the time evolution of zonal mean (a), zonal mean profile (b) and trend of zonal mean profile (c) derived from HIRS UTWV brightness temperatures during 1979-2013. High/low brightness temperatures represent a dry/wet upper troposphere, and indicate the descending/ascending movement of air (Bates et al., 1996; Bates and Jackson, 2001). The distance between the latitudes of maximum HIRS UTWV brightness temperatures in the Northern and Southern hemispheres can be used as a physical indicator to measure the width of the tropics (Reichler, 2009) (Figure 1a). The zonal mean HIRS UTWV brightness temperatures show a maximum in the subtropics near $22^{\circ} \mathrm{N}$ and $22^{\circ} \mathrm{S}$ and decrease gradually towards lower and higher latitudes (Figure 1b). Thus the brightness temperatures have relatively sharp gradients at the edge of the tropics (Worden et al., 2007). Brightness temperatures have increased in the zone of maximum brightness in both hemispheres, suggesting stronger subsidence and drier air (Figure 1c). Figure 2 shows the change (a) and anomaly (b) of the width of tropical belt derived from the HIRS UTWV brightness temperatures during 1979-2013 on an annual basis. The width of the tropical 
belt is defined as the zonal distance between the maximum HIRS UTWV brightness temperatures in both hemispheres. On average, the HIRS UTWV brightness temperatures have increased since the 1990s (Figure 2a). In addition the latitude of maximum brightness temperatures has increased in both hemispheres, showing poleward expansion of the Hadley circulation and the widening of the tropical belt (Figure 1a and Figure 2a). This is consistent with the results which define the width of the tropical belt as the distance between latitudes where the mean HIRS UTWV brightness temperature exceeds $250 \mathrm{~K}$ (similar to $\mathrm{Hu}$ and $\mathrm{Fu}$ (2007)). However using a lower threshold of 245 $\mathrm{K}$ for example, does not change the result very much. Both the northern and southern edges of the Hadley circulation exhibit a systematic poleward shift during 1979-2013, consistent with the results of widening of the tropical belt (Figure 2a). Based on the definition, the rate of change of the tropical belt width is 1.57 degrees latitude per decade. The trend is statistically significant and means an overall expansion of about 5.5 degrees between 1979 and 2013. Figure $2 \mathrm{~b}$ also shows the anomalies of tropical belt width after the long-term trend has been accounted for. Certain years (e.g. 2000, 2008 and 2011) show a positive anomaly, while others (e.g. 1982, 1994 and 1997) a strong negative one, which are equivalent to the La Niña and El Niño years respectively?.

To investigate spatial contrasts in widening, six domains in the tropics are defined in Table 1 . The time evolution of zonal mean HIRS UTWV brightness temperatures for the six domains are shown in Figure 3, and associated rates of widening of the tropical belt are summarized in Table 1 and plotted in Figure 4. Overall, there are different patterns in the eastern and western Pacific. In the eastern Pacific, the HIRS UTWV brightness temperatures are higher in the southern hemisphere and the northern hemisphere maximum is relatively weak. Although the width of the tropical belt has shrunk (Figure 3a), the trend is not significant. In the western Pacific there are much lower values 
near the equator (Figure 3b), suggesting a wetter troposphere. Here there has been a significant widening of the tropical belt, reaching 1.52 degrees latitude/decade $(p<0.05)$ (Figure $3 b)$. The growth of the west Pacific tropical region and the shrinkage of the east Pacific region is clear in the equatorial region (Figure 5), indicating that the strengthening of the Walker Circulation over time accounts for the phenomenon. Widening is also clear in the tropical Atlantic although the magnitude of widening is smaller (Figures $3 c$ and $4 c$ ). Over global land regions in the tropics similar changes in poleward edges of the tropical belt are observed in both Northern and Southern hemispheres with significant widening being reported in Africa (Figure 4e) and South America (Figure 4f). Thus, the most rapid widening has been reported in the west Pacific but significant increases in width are reported in 3 out of 6 regions.

\section{Discussion and Conclusions}

The HIRS UTWV brightness temperatures during 1979-2013 on an annual basis have been used to study the poleward expansion of the tropical belt. The width is defined as the distance between the latitudes with maximum HIRS UTWV brightness temperatures in the Northern and Southern hemisphere. The mean magnitude of the poleward expansion of tropical belt is 1.57 degrees latitude per decade, corresponding to 5.5 degrees during 1979-2013. The largest poleward expansion is found in the west Pacific with a rate of 1.52 degrees latitude per decade.

Sensitivity to the threshold chosen to define the width appears low but further work is needed to confirm this. Alternative definitions could use the latitude of the maximum brightness temperature (irrespective of absolute value) and subsequent research is also examining this. It is also important to look at possible asymmetry in hemispheric response as well as changes in total width and to 
correlate changes in width with changes in other atmospheric variables. This will allow us to understand whether changes in the dynamics and thermodynamics of the Hadley cell are correlated. Understanding inter-annual variability and relationship with circulation indices for example, will also uncover more information about the various forcing factors on tropical width. The magnitude of changes measured in this study are consistent with those based on other metrics, including tropical upwelling at $60 \mathrm{hPa}$ (Rosenlof, 2002), tropopause height (Seidel and Randel, 2007), troposhperic temperatures (Fu et al., 2006), total ozone (Hudson et al., 2006), jet stream separation (Archer and Caldeira, 2008), outgoing longwave radiation and mean meridional circulation ( $H u$ and $F u, 2007)$. Other estimates of widening of the tropical belt vary between 0.3 and $3.1^{\circ}$ latitude/decade (Table 2), due in part to different study periods, datasets, definitions and methods. The consensus widening averages about $1.4^{\circ}$ latitude per decade (Reichler, 2009), broadly consistent with results in this study. Associated shifts in precipitation maxima and the subtropical dry belts could lead to fundamental shifts in ecosystems and in human settlements (Seidel et al., 2008). However, Reichler (2009) comments that so far, broad shifts in climate caused by poleward expansion of the tropical belt have not been consistent. The reasons for these inconsistencies and the spatial contrasts in tropical belt dynamics/thermodynamics are important research areas for the future.

Acknowledgments. This study is supported by the National Natural Science Foundation of China (41201072), the State Key Program of National Natural Science Foundation of China (41230528), Open Research Fund Program of Plateau Atmosphere and Environment Key Laboratory of Sichuan Province (PAEKL-2014-K1), and Jiangsu Specially-Appointed Professor project. This study is also funded by "the Priority Academic Program Development of Jiangsu Higher Education Institutions" 
178

179

180

181

182

183

184

185

186

187

188

189

190

191

192

193

194

195

(PAPD). We are very grateful to the reviewers for their constructive comments and thoughtful suggestions.

\section{References}

Archer, C. L., and K. Caldeira (2008), Historical trends in the jet streams, Geophysical Research Letters, 35(8), L08803.

Bates, J. J., et al. (1996), Interannual variability of upper-troposphere water vapor band brightness temperature, Journal of Climate, 9(2), 427-438.

Bates, J. J., and D. L. Jackson (2001), Trends in upper-tropospheric humidity, Geophysical Research Letters, 28(9), 1695-1698.

Bates, J. J., et al. (2001), Variability of tropical upper tropospheric humidity 1979-1998, Journal of Geophysical Research-Atmospheres, 106(D23), 32271-32281.

Fu, Q., et al. (2006), Enhanced mid-latitude tropospheric warming in satellite measurements, Science, 312(5777), 1179-1179.

Fu, Q., and P. Lin (2011), Poleward shift of subtropical jets inferred from satellite-observed lower stratospheric temperatures, Journal of Climate, in press.

Hu, Y., and Q. Fu (2007), Observed poleward expansion of the Hadley circulation since 1979, Atmospheric Chemistry and Physics, 7(19), 5229-5236.

Hu, Y., et al. (2011), Observational Evidence for Poleward Expansion of the Hadley Circulation, Advances in Atmospheric Sciences, 28(1), 33-44. 
Hudson, R. D., et al. (2006), The total ozone field separated into meteorological regimes - Part II:

Northern Hemisphere mid-latitude total ozone trends, Atmospheric Chemistry and Physics, 6, 5183-5191.

Jackson, D. L., and B. J. Soden (2007), Detection and correction of diurnal sampling bias in HIRS/2 brightness temperatures, Journal of Atmospheric and Oceanic Technology, 24(8), 1425-1438.

Johanson, C. M., and Q. Fu (2009), Hadley Cell Widening: Model Simulations versus Observations, Journal of Climate, 22(10), 2713-2725.

Korty, R. L., and T. Schneider (2008), Extent of Hadley circulations in dry atmospheres, Geophysical Research Letters, 35(23), L23803.

Lu, J., et al. (2007), Expansion of the Hadley cell under global warming, Geophysical Research Letters, 34(6), L06805.

Lu, J., et al. (2009), Cause of the widening of the tropical belt since 1958, Geophysical Research Letters, 36, L03803.

Reichler, T., et al. (2003), Determining the tropopause height from gridded data, Geophysical Research Letters, 30(20), 2042.

Reichler, T. (2009), Changes in the atmospheric circulation as indicator of climate change, in: Climate change: Observed impacts on planet Earth, T. M. Letcher, Ed., Elsevier BV, The Netherlands, ISBN: 9780-444-53301-2, pp. 145-164.

Rosenlof, K. H. (2002), Transport changes inferred from HALOE water and methane measurements, Journal of the Meteorological Society of Japan, 80(4B), 831-848.

Seidel, D. J., and W. J. Randel (2007), Recent widening of the tropical belt: Evidence from tropopause observations, Journal of Geophysical Research-Atmospheres, 112(D20), L03803.

Seidel, D. J., et al. (2008), Widening of the tropical belt in a changing climate, Nature Geoscience, 1(1), 
223 Sen, P. K. (1968), Estimates of regression coefficient based on Kendall's tau, Journal of the American 224 Statistical Association, 63, 1379-1389.

225 Shi, L., and J. J. Bates (2011), Three decades of intersatellite-calibrated High-Resolution Infrared

226 Radiation Sounder upper tropospheric water vapor, Journal of Geophysical Research-Atmospheres,

$227116, \mathrm{D} 04108$.

228 Soden, B. J., and F. P. Bretherton (1993), Upper tropospheric humidity from the GEOS $6.7 \mathrm{~mm}$

229 channel: Method and climatology for July 1987, J. Geophys. Res., 98(D14), 16,669-16,688,

230 doi:10.1029/93JD01283.

231 Worden, J., et al. (2007), Importance of rain evaporation and continental convection in the tropical water 232 cycle, Nature, 445(7127), 528-532.

233 Žagar, N., et al. (2011), Climatology of the ITCZ derived from ERA Interim reanalyses, Journal of 

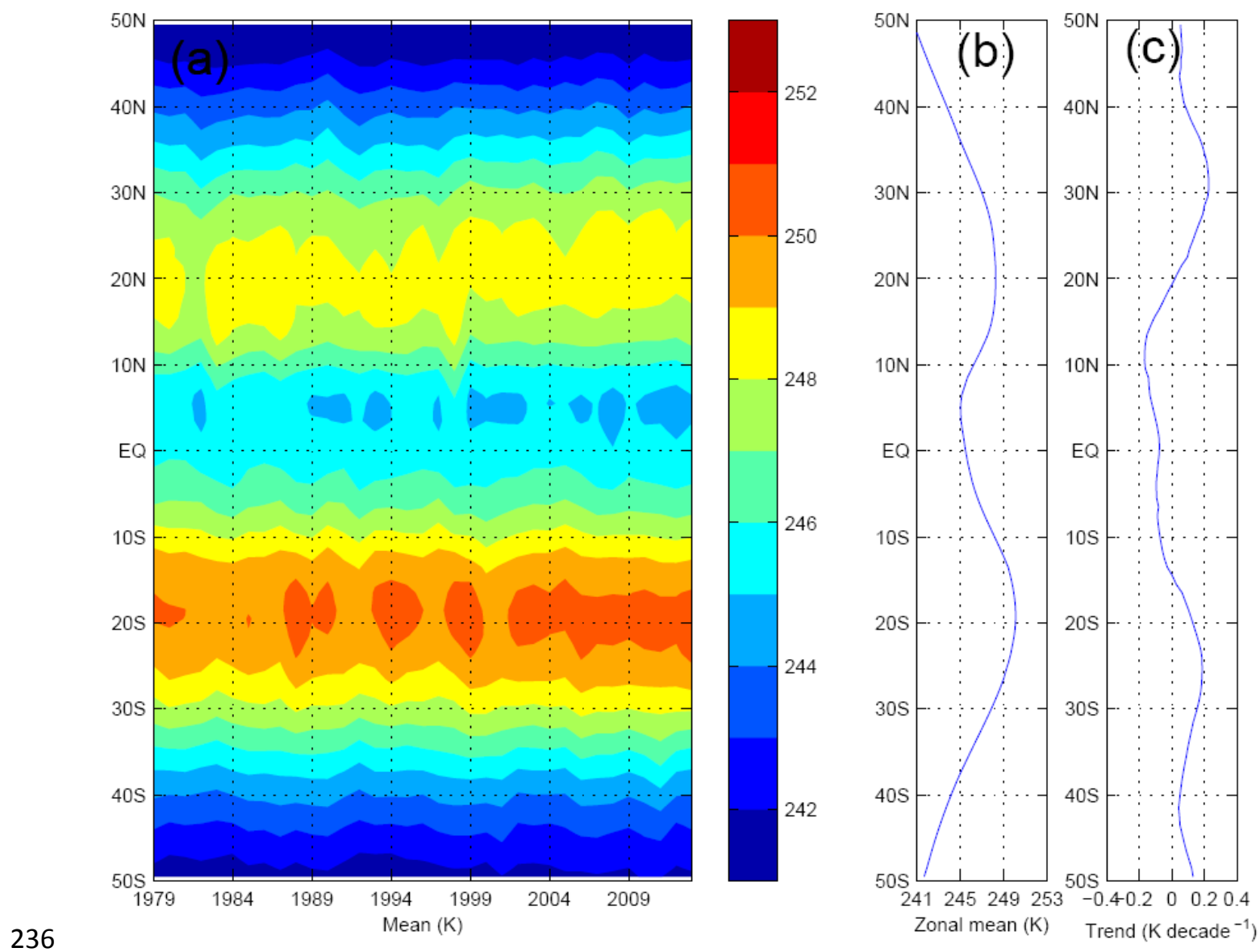

Figure 1. Time evolution of zonal mean (a), zonal mean profile (b) and trend of zonal mean profile

(c) derived from the HIRS UTWV brightness temperatures during 1979-2013 on an annual basis.

Units of zonal mean and trend of brightness temperatures are $\mathrm{K}$ and $\mathrm{K}$ per decade, respectively.

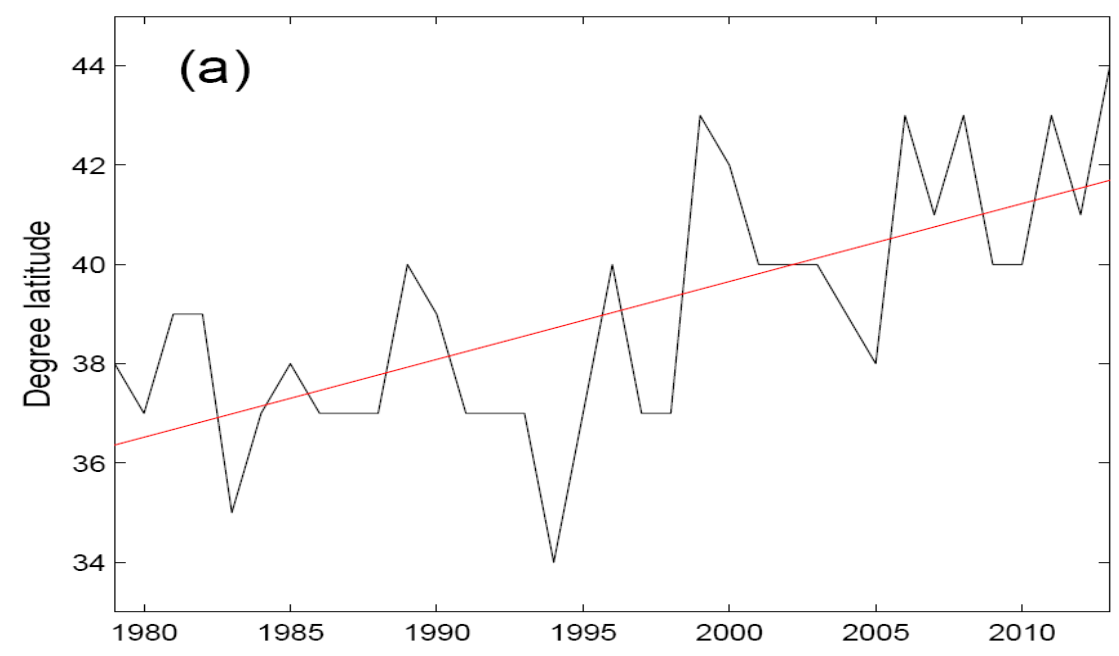




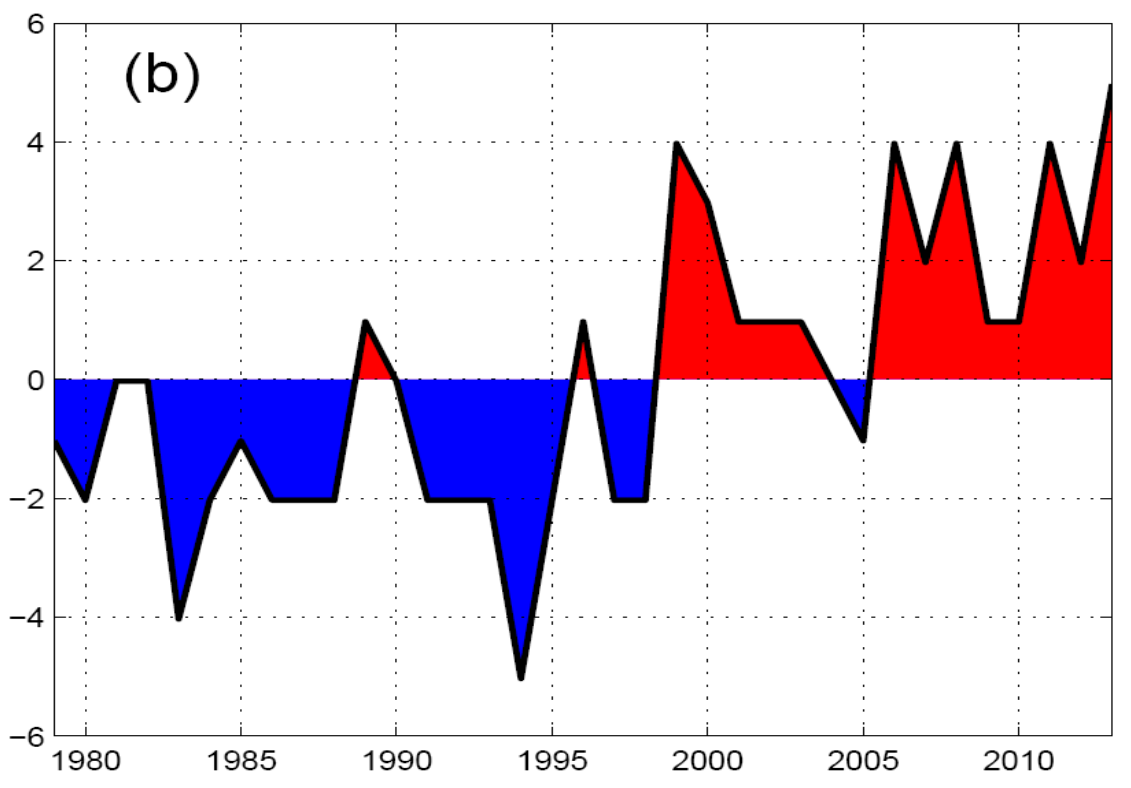

Figure 2. Change (a) and anomaly (b) of the width of tropical belt derived from the HIRS UTWV brightness temperatures during 1979-2013 on an annual basis. The width of tropical belt is defined as the zone distance between the maximum HIRS UTWV brightness temperatures in the Northern and Southern hemisphere. 
(a) East Pacific

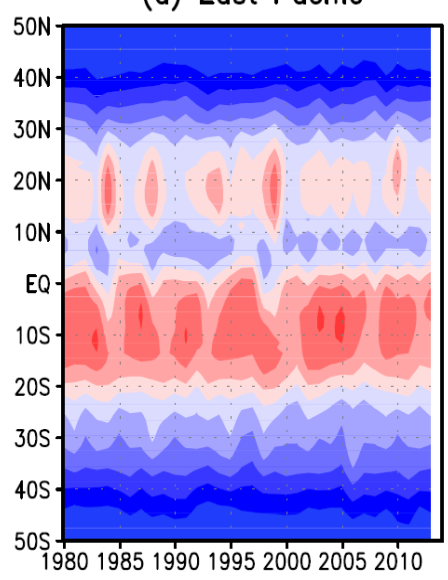

(d) Indian

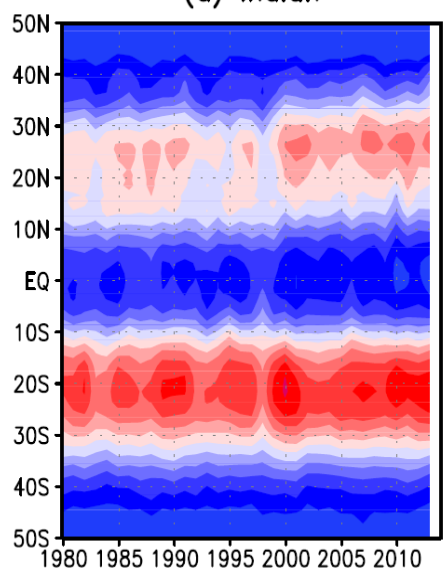

(b) West Pacific

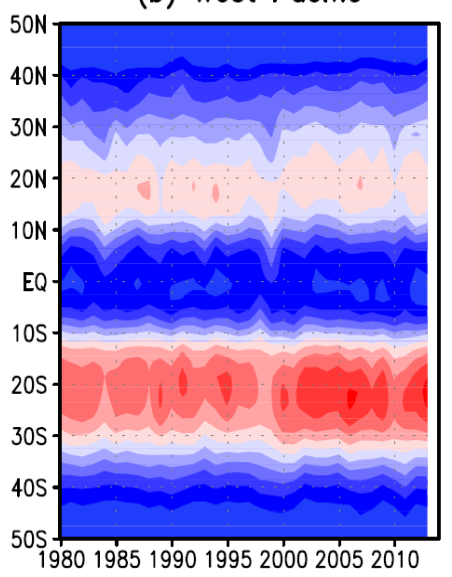

(e) Africa

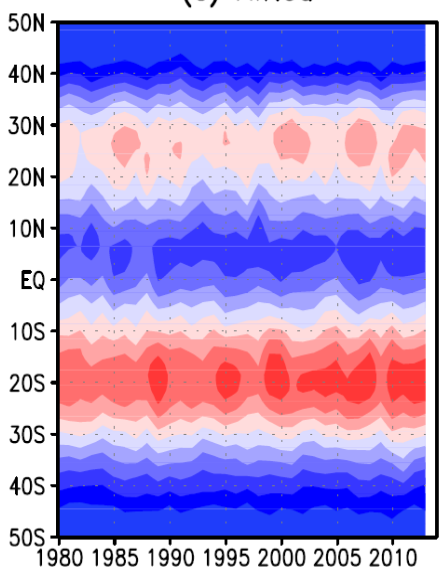

(c) Atlantic

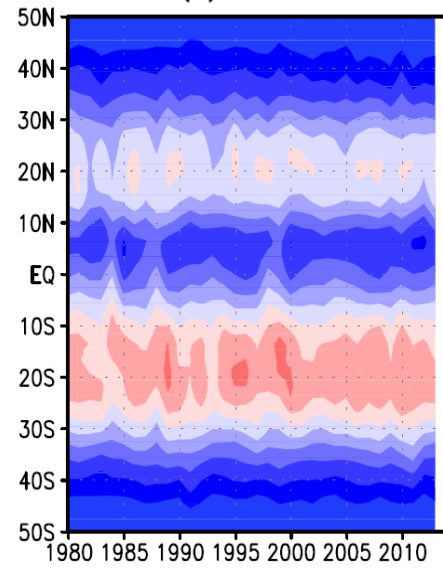

(f) South America

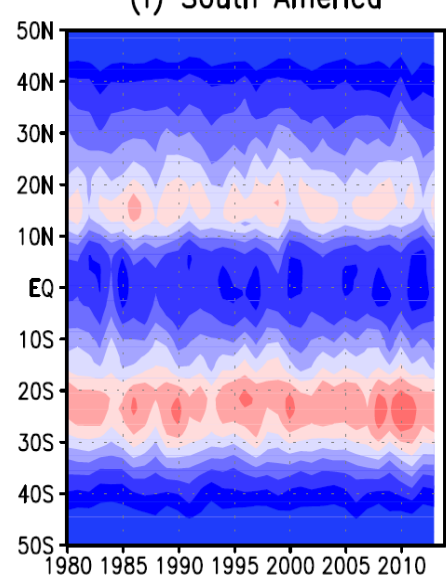

Figure 3. Time evolution of zonal mean HIRS UTWV brightness temperatures for six regions 

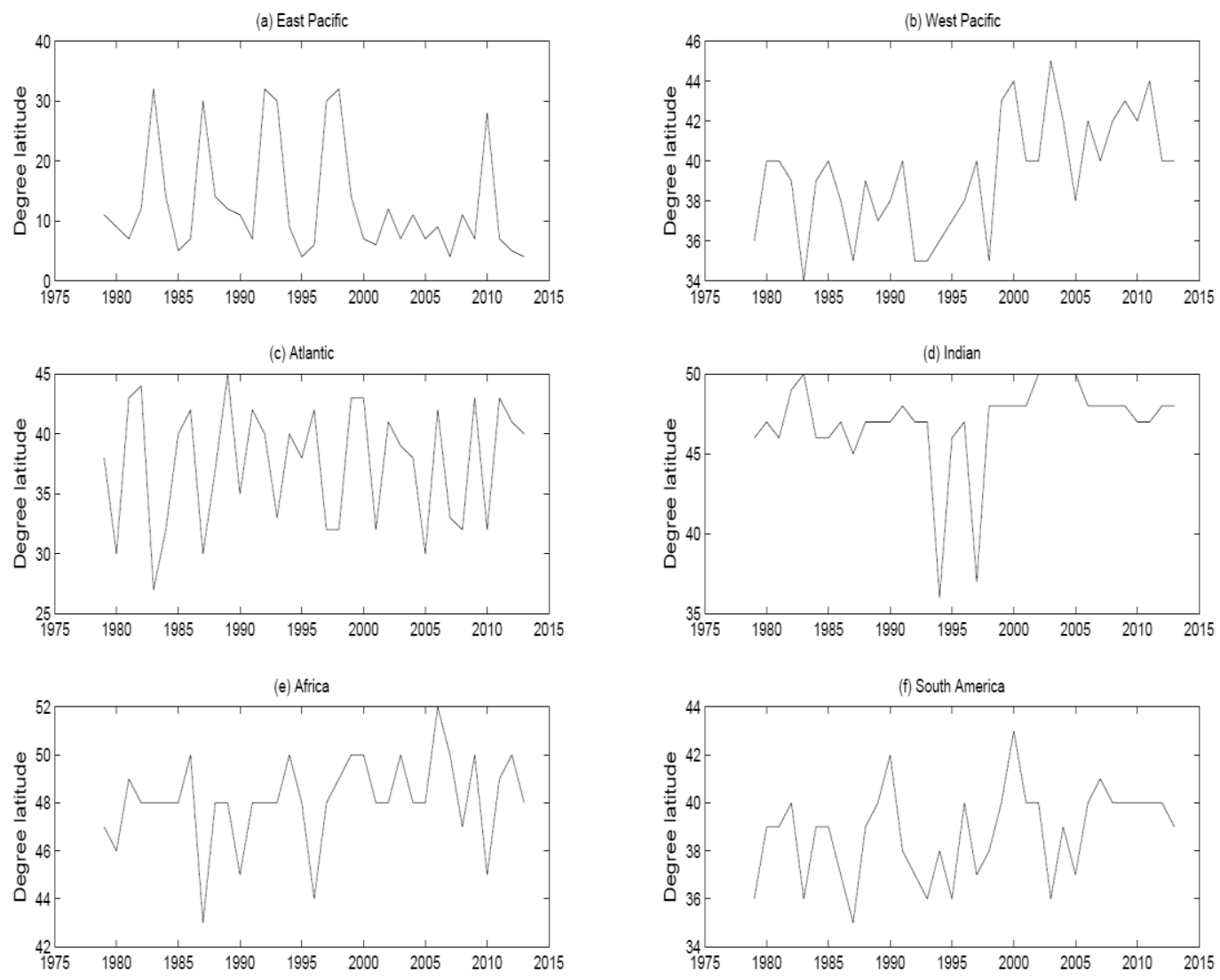

Figure 4. Change of the width of the tropical belt for six regions defined in Table 1 during 1979-

South America. 

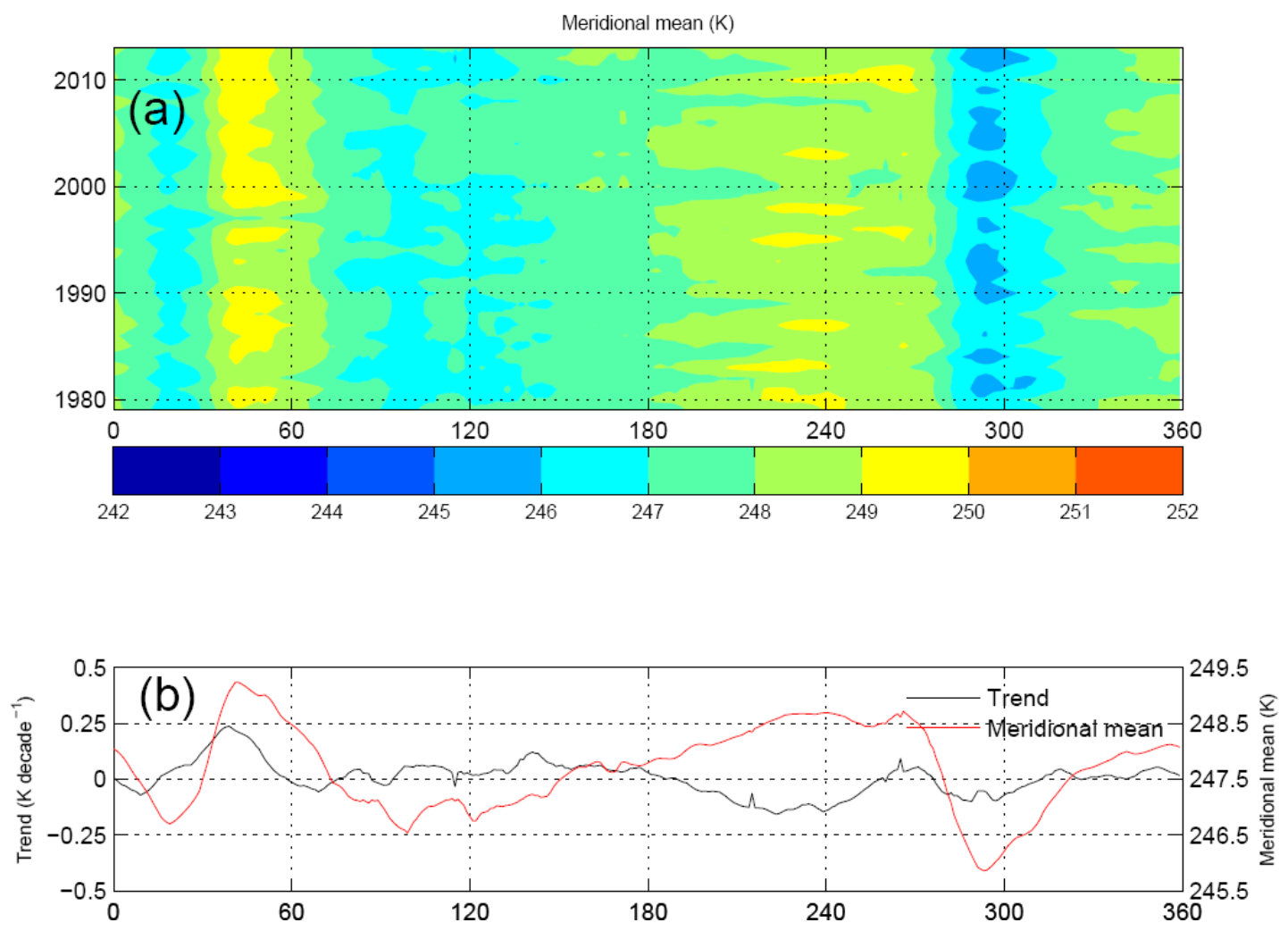

Figure 5. Time evolution of meridional mean (a), meridional mean profile and trend of meridional annual basis. Others are same as as Figure 1. 
282

283

284

285

286 bold.

\begin{tabular}{ccccc}
\hline Region & $\begin{array}{c}\text { Longitude } \\
\text { range (degree) }\end{array}$ & Trend & $\mathrm{p}$ & Std \\
\hline Globe & $0-360$ & $\mathbf{1 . 5 7}$ & 0.0001 & 2.43 \\
East Pacific & $180-275$ & -1.83 & 0.0583 & 9.39 \\
West Pacific & $100-180$ & $\mathbf{1 . 5 2}$ & 0.0022 & 2.87 \\
Atlantic & $290-10$ & 0.41 & 0.74 & 5.12 \\
Indian & $45-100$ & $\mathbf{0 . 5 5}$ & 0.011 & 2.92 \\
Africa & $340-50$ & 0.52 & 0.059 & 1.84 \\
South America & $275-325$ & $\mathbf{0 . 6 3}$ & 0.033 & 1.87 \\
\hline
\end{tabular}

Table 1. Longitudinal limits for the six regions defined in the previous study (Žagar et al., 2011) and used in this paper. Widening rates (degree latitude per decade), $\mathrm{p}$ value as well as standard deviation (std) of the total width of the tropical belt derived from HIRS UTWV brightness temperatures during 1979-2013 are shown in table. Trends significant at $\mathrm{p}<0.05$ are highlighted in
287

288

289

290

291

292

293

294

295

296

297

298

299

300

301

302

303

304

305

306

307

308

309

310

311

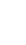


312 Table 2. Comparison with the widening of the tropical belt estimated from other studies. The unit

313 is degree latitude per decade.

\begin{tabular}{|c|c|c|c|c|}
\hline Indicator & Datasets & Widening & Period & Sources \\
\hline $\begin{array}{l}\text { Upper tropospheric water } \\
\text { vapor } \\
\text { temperatures }\end{array}$ & $\begin{array}{l}\text { Intersatellite-calibrated } \\
\text { High-resolution infrared } \\
\text { radiation sounder (HIRS) }\end{array}$ & 1.57 & 1979-2013 & This study \\
\hline Tropical upwelling at $60 \mathrm{hPa}$ & $\begin{array}{l}\text { Halogen occultation } \\
\text { experiment (HALOE) }\end{array}$ & 3.0 & 1992-2001 & (Rosenlof, 2002) \\
\hline Tropopause height & $\begin{array}{l}\text { Radiosonde } \\
\text { Reanalyses }\end{array}$ & $1.8-3.1$ & 1979-2005 & $\begin{array}{l}\text { (Seidel and Randel, } \\
\text { 2007) }\end{array}$ \\
\hline Tropospheric temperatures & $\begin{array}{l}\text { Microwave sounding unit } \\
\text { (MSU) }\end{array}$ & 0.7 & 1979-2005 & (Fu et al., 2006) \\
\hline $\begin{array}{l}\text { Total ozone (Northern } \\
\text { hemisphere only) }\end{array}$ & $\begin{array}{l}\text { Total Ozone Mapping } \\
\text { Spectrometer (TOMS) }\end{array}$ & 1.0 & 1979-1991 & (Hudson et al., 2006) \\
\hline Jet stream separation & Reanalyses & 0.3 & 1979-2001 & $\begin{array}{l}\text { (Archer and Caldeira, } \\
\text { 2008) }\end{array}$ \\
\hline Jet stream separation & Reanalyses & 1.0 & 1979-2005 & (Seidel et al., 2008) \\
\hline Mean meridional circulation & Reanalyses & 1.0 & 1979-2005 & (Hu and $F u, 2007)$ \\
\hline Outgoing longwave radiation & Various satellite sensors & 1.5 & 1979-2005 & (Hu and Fu, 2007) \\
\hline
\end{tabular}

